Revista lus et Praxis, Año 26, № 1, 2020, pp. 149 - 170

ISSN 0717 - 2877

Universidad de Talca - Facultad de Ciencias Jurídicas y Sociales

La responsabilidad penal de las personas jurídicas en el derecho ecuatoriano

Frank Mila

Trabajo recibido el 5 de marzo de 2019 y aprobado el 31 de julio de 2019

\title{
La responsabilidad penal de las personas jurídicas en el derecho ecuatoriano
}

\author{
CRIMINAL LIABILITY OF LEGAL PERSONS IN ECUADORIAN LAW
}

FRANK MILA ${ }^{1}$

RESUMEN

Este trabajo de investigación está dirigido a realizar un análisis jurídico-penal de la responsabilidad penal de la persona jurídica en el Derecho ecuatoriano. En tal sentido, se analiza este régimen de responsabilidad conforme al Código Orgánico Integral Penal que entró en vigencia en el año 2014 y estatuyó de manera primigenia a las personas jurídicas como sujetos susceptibles de una pena. En tal sentido, se estudian las generalidades en relación a la Responsabilidad Penal de las Personas Jurídicas, así como la regulación específica que realiza la legislación ecuatoriana, particularmente los elementos normativos que estatuyen los tipos relacionados con esta responsabilidad, posteriormente se estudia el régimen de penas (medidas) que pueden imponerse a una persona jurídica y por último, se abordan los aspectos procesales relacionados con la aplicación de los tipos penales en contra de estos entes.

ABSTRACT

This research work is aimed at conducting a legal-criminal analysis of the criminal liability of the legal person in Ecuadorian law. In this regard, this liability regime is analyzed in accordance with the Comprehensive Criminal Organic Code that entered into force in 2014 and originally established legal persons as subjects subject to a penalty. In this regard, the generalities are studied in relation to the criminal liability of legal persons, as well as the specific regulation that makes Ecuadorian legislation, particularly the regulatory elements that provide the types related to this responsibility, then the penalty regime is studied (measures) that can be imposed on a legal person and finally, the procedural aspects related to the application of the criminal offenses against these entities are addressed.

PALABRAS CLAVE

Responsabilidad Penal de las Personas Jurídicas, dogmática penal, teoría del delito, responsabilidad penal.

KEY WORDS

Criminal responsibility of legal persons, criminal dogmatics, theory of crime, criminal responsibility.

\section{A modo de introducción: generalidades acerca de la Responsabilidad Penal de las Personas Jurídicas}

Históricamente, en el campo del Derecho penal se ha hecho referencia al aforismo societas delinquere non potest ${ }^{2}$, relacionado con la afirmación que las sociedades no pueden delinquir ${ }^{3}$, por tanto, las personas jurídicas no pueden ser responsables penalmente. En tal sentido, el fundamento

\footnotetext{
1 PhD en Derecho. PhD en Educación. Docente - Investigador de la Universidad de Otavalo. Otavalo, Ecuador. Email: fmila@uotavalo.edu.ec.

${ }^{2}$ Algunos autores hacen referencia a su carácter de principio, entre ellos MUÑOZ Y GARCÍA (2010) p. 627; BAJO (2009) p. 31; COBO (2015), p. 389; AGUDO (2016) p, 19; ZUGALDÍA (2010) p. 1; BAJO Y BACIGALUPO (2001), p. 67; y en el Derecho ecuatoriano específic amente, BASABE (2003) p. 17 y entre otros.

${ }^{3}$ Zaffaroni agrega que "En realidad, la cuestión de la Responsabilidad Penal de las Personas Jurídicas es muy antigua y tuvo particular vigencia cuando nació el interés por el llamado derecho penal económico, siendo tema de discusión de mediados de siglo pasado -en que la responsabilidad solía fundarse con argumentos kelsenianos-, de modo que no constituye ninguna novedad en el campo de la parte general del derecho penal". ZAFFARONI (005) p. 147.
} 
clásico que ha acompañado al aludido aforismo para negar la aludida responsabilidad penal, ha sido la incapacidad de acción, de culpabilidad y de pena ${ }^{4}$ de las personas jurídicas.

En efecto, el estudio estratificado del delito se realiza abordando en primer término: la acción $^{5}$, es el punto de partida de toda reacción jurídico-penal y el objeto al que se agregan determinados predicados (tipicidad, antijuricidad y culpabilidad), que convierten esa conducta en punible ${ }^{6}$, lo cual significa que el primer elemento del delito está conformado por la denominada conducta, siendo esta entendida, según como una conducta humana significativa en el mundo exterior, que es dominada o al menos dominable por la voluntad? ${ }^{7}$.

Así, tenemos que la acción es el primer elemento del delito y se circunscribe a la conducta humana capaz de modificar el mundo exterior y en la cual está presente la voluntad (por tal razón se excluye la acción cuando existen causas capaces de limitar la voluntad, $p$ ej. fuerza física irresistible, estado de sueño, entre otras). En lo atinente a la incapacidad de acción que poseen las personas jurídicas, se sostiene que las personas jurídicas no tienen responsabilidad, en virtud que siempre quien materializa la conducta es una persona física, así que el argumento fuerte es que la responsabilidad debe recaer exclusivamente sobre estos, sean directores, administradores o empleados, quienes serán los que dominarán la voluntad de las personas jurídicas.

Por otra parte, la otra limitación que existe con respecto a admitir este tipo de responsabilidad radica en aducir que las personas jurídicas carecen de capacidad de culpabilidad, por ello, siguiendo el concepto de culpabilidad, "la acción típica y antijurídica ha de ser culpable, es decir, ha de poderse hacer responsable de ella al autor, la misma se le ha de poder, como mayoritariamente se dice, 'reprochar'" 8 . Vista la referida definición, las respuestas y argumentos que usualmente se emplean para afirmar la incapacidad de culpabilidad, son similares a los de la acción, en virtud que se sostiene que a una persona jurídica no se le puede hacer responsable por sí sola de una acción, típica y antijurídica, en virtud que el reproche únicamente se puede realizar en relación a una persona física. Asimismo, es oportuno indicar que, para justificar la capacidad de culpabilidad de la persona jurídica, es sustentada en diversas teorías ${ }^{9}$.

Por último, se argumenta que las personas jurídicas son incapaces de ser acreedoras de una pena ${ }^{10}$. Al respecto, es preciso destacar que desde hace más de dos mil años se ha intentado responder a la pregunta por la naturaleza de la pena con un gran número de puntos de vista, razón por la cual apenas resulta pensable que puedan existir nuevas respuestas ${ }^{11}$. Así, se han estructurado tres grandes teorías para justificar la función de la pena, divididas en teorías absolutas, teorías relativas y las más recientes, denominadas teorías de la unión, que concilian en parte aspectos de las teorías absolutas y relativas y crean una nueva concepción, en las cuales se destaca más el aspecto preventivo. Por ello, es posible aducir que las personas jurídicas son incapaces de ser

\footnotetext{
${ }^{4}$ Así lo abordan: BAJO (2009), p. 31; MIR (2006), p. 195; MUÑOZ (2010), p. 627; BAJO Y BACIGALUPO (2008) p. 803; AGUDO (2016), p. 29 y en Ecuador, BASABE (2003) p. 22, entre otros.

${ }^{5}$ Nos referimos al término acción o conducta de manera indistinta, entendiendo que se trat a del primer elemento estratificado del estudio del delito.

${ }^{6}$ MUÑOZ (2010), p. 213.

${ }^{7}$ ROXIN (1997), p. 194.

${ }^{8}$ ROXIN (1997). p. 195.

${ }^{9}$ Entre ellas: 1.- Culpabilidad por conciencia especial de la persona jurídica, 2.- culpabilidad por el espíritu normativo de la persona jurídica, 3.- culpabilidad funcional del órgano, 4.- culpabilidad por no evitación de los fallos organizativos de la persona jurídica, 5.- culpabilidad por no evitación de las influencias criminógenas de la persona jurídica, 6.- culpabilidad por el carácter de la empresa, 7.- culpabilidad por la conducción de la actividad empresarial, 8-culpabilidad por reprochabilidad ético-social empresarial, 9.- culpabilidad por defecto de organización y, 10.-culpabilidad de la persona jurídica por su cultura empresarial de incumplimiento de la legalidad (concepto constructivista de culpabilidad de la persona jurídica), todas abordadas en PÉREZ (2014).

${ }^{10}$ Con respecto a la pena, se debe atender a la función del derecho penal que precisamente responde a las teorías de la pena.

11 BACIGALUPO (1996), p. 12.
} 
destinatarias de los fines de la pena, ya que en virtud de la principal característica de la pena es su fin preventivo, por tal razón, es un medio de prevención, al servicio de la protección efectiva de los ciudadanos, asignándole la función de crear expectativas sociales que motiven a la colectividad en contra de la comisión de delitos ${ }^{12}$.

Ante tal escenario, la doctrina afirma que entre los objetivos que persigue la imposición de la pena se encuentran los de prevención general, deducidos a partir de la acción teleológica del aparato estatal en cuanto se refiere a brindar seguridad jurídica y social a sus conciudadanos; y los de prevención específica o especial, que hacen relación al proceso de reelaboración de los códigos normativos y de conducta del agente imputado en torno a una escala de valores plenamente aceptados dentro de la sociedad y tenidos como legítimos ${ }^{13}$. Visto lo anterior se deduce lo complejo que resulta atribuir capacidad de pena a las personas jurídicas, en virtud que no se logra delimitar que sean receptoras de los fines preventivos. Asimismo, el hecho de estatuir una pena específica a las personas jurídicas (p. ej. multa), ello no representa por sí solo que se cumpla con el fin de la pena.

Ahora bien, indistintamente de la delimitación del societas delinquere non potest, así como de las consideraciones generales que apuntan a sustentar este dogma, sustentados en la idea de incapacidad de acción, de culpabilidad y de pena de las personas jurídicas, actualmente se han ido desplazando tales argumentos, que incluso entienden la ficción que implica hablar de responsabilidad de sociedades, en virtud que realmente quien materializa una acción delictiva siempre es una persona física, la teoría del delito ha ido reelaborándose, en el sentido de superar la limitación existente relacionada con la idea que la teoría del delito fue concebida para personas naturales, y parte de la doctrina se ha enfocado en estudiar y enarbolar la posibilidad de atribuir responsabilidad penal a las personas jurídicas, mediante el desarrollo de sistemas legislativos que posibiliten este fenómeno.

Al respecto, parte de la doctrina afirma que la persona individual y la persona colectiva son sistemas que deben ser tratados por el Derecho Penal de forma idéntica y los conceptos que son válidos para un sistema (psicofísico) se pueden trasladar sin problemas - con los matices correspondientes - a otro sistema como la empresa ${ }^{14}$.

De igual manera, este tipo de responsabilidad colectiva es producto de la influencia del ordenamiento más poderoso del mundo, el de los Estados Unidos, donde desde la época del ferrocarril descubrieron y temieron el poder de las corporaciones, y descubrieron que para dominarlo hacían falta, aparte de la Sherman Act, la instauración de la responsabilidad colectiva ${ }^{15}$.

Visto lo anterior, al margen de Gran Bretaña y Holanda, en el resto de Europa el reconocimiento de una responsabilidad penal de las corporaciones y empresas es relativamente reciente y se encuentra en progresión, en contraste con la controversia existente sobre el problema en EE.UU., donde dicha responsabilidad se depura criminalmente desde hace más de un siglo ${ }^{16}$.

En tal sentido, existe una tendencia creciente en el Derecho europeo continental a reconocer la responsabilidad penal de la propia persona jurídica; en esa línea, además de la implementación en el Código penal francés de una regla de responsabilidad directa de la propia persona jurídica y la posible futura introducción en el Código penal español de una reforma ${ }^{17}$ a favor

\footnotetext{
${ }^{12} \operatorname{MIR}(1982)$, p. 42.

${ }^{13}$ BASABE (2003), pp. 18-19.

${ }^{14}$ FEIJOO (2002), p. 42.

${ }^{15}$ NIETO (2008), pp. 131-132.

${ }^{16}$ BOLDOVA (2013), p. 224.

${ }^{17}$ DONAIRES (2013), p. 2.
} 
de responsabilizar directamente a la persona jurídica, se observa cómo el Corpus Juris europeo destinado a la protección de los intereses financieros de la Unión Europea muestra en su artículo 13 (anteriormente artículo 14) una disposición de responsabilidad penal directa de las corporaciones ${ }^{18}$.

Lo supra indicado se ha reflejado en diversos países entre los cuales figuran, integrantes de la Unión Europea: España ${ }^{19}$, Rumanía ${ }^{20}$, Portugal ${ }^{21}$ y la República Checa ${ }^{22}$, por su parte, en América, vale destacar a los Estados Unidos de Norteamérica (a pesar de tratarse de un Estado en el cual rige el sistema anglosajón, se ha desarrollado un sistema de Responsabilidad Penal de las Personas Jurídicas complejo que consagra esta responsabilidad), de igual manera destacan Chile ${ }^{23}$, Perú $^{24}$, y más recientemente Ecuador ${ }^{25}$ entre otros países ${ }^{26}$, han consagrado en sus legislaciones, este tipo de responsabilidad que demuestran que se va abandonando progresivamente el societas delinquere non potest, para dar paso a un societas delinquere potest ${ }^{27}$.

De igual manera, la responsabilidad colectiva va tomando fuerza en virtud de la dificultad existente para individualizar delincuentes dentro de un entramado empresarial ${ }^{28}$. Ahora bien, son diversos los sistemas de imputación de la responsabilidad penal de la persona jurídica, así encontramos básicamente los siguientes:

1.- Modelos de Responsabilidad Penal Indirecta de las Personas Jurídicas ${ }^{29} ; 1.1$ Responsabilidad Vicaria (Vicarious Liability), siendo que este se entiende en términos generales que cuando obra la persona física que representa a la empresa cometiendo un delito, entonces también lo está cometiendo la empresa misma ${ }^{30}$; 1.2.- High Managerial Test: Visto que con el transcurrir del tiempo se constató la amplitud y la inadecuación teórica y práctica del modelo básico vicarial, en Estados Unidos se procedió a su restructuración en la elaboración del Código Penal Modelo,

${ }^{18}$ DONAIRES (2013), p. 2.

${ }^{19}$ En España se manejaron algunos instrumentos relativos a la responsabilidad de las personas jurídicas, sin embargo, es con la entrada en vigencia de la Ley Orgánica 5/2010 de año 2010, que reguló la responsabilidad de la persona jurídica y penas aplicables.

${ }^{20}$ La responsabilidad penal de la persona jurídica surge en el año 2006. A partir de este momento, de acuerdo con la Ley $278 / 2006$ de año 2006, el Código Penal vigente introdujo un conjunto de normas jurídicas que establecen el régimen jurídico que se aplica a esta institución. La persona jurídica es directamente responsable y esta responsabilidad puede funcionar independientemente de la responsabilidad penal de la persona física (es decir, la persona jurídica pueda ser considerada penalmente responsable, aun cuando la persona física no lo sea -por ejemplo, si la persona física murió). DAMASCHIN Y GORUNESCU (2014).

${ }^{21}$ En Portugal se reformó el Código Penal mediante Ley № 59/2007 de año 2007, referida a la responsabilidad penal de las empresas, modificándose de esa manera el artículo 11 del Código Penal, que estatuía la responsabilidad penal exclusivamente enfocada en las personas naturales, así se amplía, para determinados delitos esta responsabilidad, tales como delitos contra la salud pública, medio ambiente o de legitimación de capitales.

22 En la República Checa, a partir de 2012, y en virtud de la nueva Ley son responsables las personas jurídicas por los delitos cometidos en beneficio, interés o en el marco de sus actividades. Tales delitos pueden ser cometidos por miembros del cuerpo de dirección o cualquier otra persona autorizada para actuar en nombre de la entidad legal; también los cometidos por cualquier persona que supervise las actividades en la entidad legal o que ejerza una influencia decisiva en la gestión de la entidad, siempre que se demuestre que la conducta de tal persona constituye por lo menos una de las condiciones para que concurra la responsabilidad de la persona legal. DE LA CUESTA Y PÉREZ (2013), p. 47.

${ }^{23}$ Se introdujo la responsabilidad de las personas jurídicas gracias a la Ley № 20.393, de año 2009, siendo similar que el caso de España, ya que previamente existían algunas disposiciones que contemplaban consecuencias para las personas jurídicas, sin que se tratara de un sistema de responsabilidad penal completo.

${ }^{24}$ Tal como se desprende de lo comentado DíAZ Y CHANJAN (2016): Mediante la Ley que Regula la Responsabilidad Administrativa de las Personas Jurídicas por el Delito de Cohecho Activo Transnacional, en la que se introduce un sistema para hacer penalmente responsables a las empresas y personas jurídicas en general - aun cuando se señala expresamente que se trata de una responsabilidad de naturaleza "administrativa»- p. 351.

${ }^{25}$ Sistema que será analizado en el presente artículo.

${ }^{26}$ Ya que existe el caso de algunos países que no cuentan con un sistema propiamente dicho, sin embargo, alguna de sus normas e incluso la doctrina, hacen referencia a la existencia de esta responsabilidad.

27 Incluso, se erigen diversas teorías para fundamentar esta posibilidad, entre las que destacan: 1.- Principio de agencia; 2.- Principio de Dirección; 3.- Principio de funcionalidad; 4.- Principio de identidad. CABEZA (2018) p. 129 ss.

${ }^{28}$ GRANADOS (2007), p. 127.

${ }^{29}$ También denominado modelo por representación.

${ }^{30}$ ROBLES (2006), p. 5. 
consistente en la restricción de la imputación al enfocarse exclusivamente en la conducta desplegada por los administradores de la empresa ${ }^{31}$; 1.3.- Teoría del Conocimiento Colectivo (collective knowledge doctrine): que consiste en imputar a la empresa la suma de los conocimientos de los empleados, cuando sea imposible lograr determinar con exactitud o precisión al verdadero responsable de la comisión del tipo ${ }^{32}$.

2. Modelos de Responsabilidad Penal Propia o Directa de las Personas Jurídicas ${ }^{33}$ : este modelo atribuye expresamente la responsabilidad penal a la persona jurídica, el acto se atribuye al órgano que es la propia persona jurídica.

Así, es el modelo que le atribuye directamente a la persona jurídica la culpabilidad por su propia actuación, el cual ha sido aplicado por el Common Law en países como Holanda, Suiza y Austria; en este sentido, las empresas son susceptibles de ser responsables penalmente ya que estarían dotadas de mecanismos autónomos de organización para poder ser imputados por sus acciones ilícitas ${ }^{34}$. Precisamente, en este modelo no se atribuye a la persona jurídica lo realizado por su representante, sino que la responsabilidad de la persona jurídica se construye a partir de la infracción de deberes propios que incumben exclusivamente a esta ${ }^{35}$.

Este modelo se sustenta en diversas teorías relativas a la culpabilidad de la persona jurídica, tales como la culpabilidad por defectos de organización, entre otras ${ }^{36}$.

\section{Regulación de la Responsabilidad Penal de las Personas Jurídicas en el Código Orgánico Integral Penal (2014)}

Con la entrada en vigencia del Código Orgánico Integral Penal $(2014)^{37}$, se marcó un antes y un después en la temática, en virtud que se consagró un capítulo de manera primigenia, relativo al régimen relativo a la Responsabilidad de las personas jurídicas, el cual se constituye básicamente de dos artículos (artículos 49 y 50) ${ }^{38}$, así como de diversas disposiciones dispersas en otros capítulos del Código, relativas a la responsabilidad aquí estudiada ${ }^{39}$. En tal sentido, el principal artículo es el 49 del Código Orgánico Integral Penal (2014), el cual consagra el régimen de responsabilidad en los siguientes términos:

Artículo 49.- Responsabilidad de las personas jurídicas.- En los supuestos previstos en este Código, las personas jurídicas nacionales o extranjeras de derecho privado son penalmente responsables por los delitos cometidos para beneficio propio o de sus asociados, por la acción u omisión de quienes ejercen su propiedad o control, sus órganos de gobierno o administración, apoderadas o apoderados, mandatarias o mandatarios, representantes legales o convencionales, agentes, operadoras u operadores, factores, delegadas o delegados, terceros que contractualmente o no, se inmiscuyen en una actividad de gestión, ejecutivos principales o quienes cumplan actividades de administración, dirección y supervisión y, en general, por quienes actúen bajo órdenes o instrucciones de las personas naturales citadas. La responsabilidad penal de la persona jurídica es

\footnotetext{
${ }^{31}$ GONZÁLEZ (2013), p. 76.

32 GÓMEZ (2006), p. 31.

${ }^{33}$ También denominado modelo por hecho propio.

${ }^{34}$ GONZÁLEZ (2013), p. 76.

${ }^{35}$ ROBLES (2006), p. 6.

${ }^{36}$ Ver a PÉREZ (2014).

${ }^{37}$ Código que unifica y sistematiza las disposiciones de la parte general y especial del Derecho Penal, así como los aspectos adjetivos penales.

${ }^{38}$ A pesar que existen otros artículos que hacen referencia a la Responsabilidad Penal de las Personas Jurídicas, entre los que destacan el relativo a la pena de estos entes.

${ }^{39}$ Tales como algunos tipos que incluyen un apartado relativo a las personas jurídicas y a la imposición de penas a estos entes.
} 
independiente de la responsabilidad penal de las personas naturales que intervengan con sus acciones u omisiones en la comisión del delito. No hay lugar a la determinación de la responsabilidad penal de la persona jurídica, cuando el delito se comete por cualquiera de las personas naturales indicadas en el inciso primero, en beneficio de un tercero ajeno a la persona jurídica. (Resaltado nuestro)

Ahora bien, del artículo anterior podemos inferir diversos aspectos, en tal sentido, para simplificar su análisis de manera estratificado, se analiza en detalle en los siguientes apartados de esta investigación, procurando abarcar todos los demás aspectos circundantes al mismo, entre los cuales destacan:

\subsection{Consideraciones acerca del sujeto activo (Codependencia de la persona natural: sistema por atribución)}

El sujeto activo de un tipo penal es definido como quien realiza el tipo, es decir, el sujeto activo es quien lleva a cabo la actividad descrita en el tipo lega $\left.\right|^{40}$. En algunas legislaciones, como la española, solo puede realizar el tipo una persona natural ${ }^{41}$, tal interpretación no se puede desprender plenamente del contenido del artículo 22 del Código Orgánico Integral Penal que estatuye que son conductas penalmente relevantes las acciones y omisiones que producen resultados lesivos, sin determinarse si se trata exclusivamente de conductas humanas, sin embargo, a la luz de la doctrina, la conducta (acción) desde el punto de vista penal siempre es considerada desde una óptica humana, lo que implica que siempre debe acarrear una traducción de la voluntad humana.

Asimismo, al revisar el contenido del artículo 49 ejusdem, se establece expresamente que las personas jurídicas serán responsable, por: la acción u omisión ${ }^{42}$ de quienes las dirigen, bien sean en condición o calidad de propietarios, administradores, apoderados, representantes, agentes, operadores, supervisores, directores, entre otros, y en fin, que actúen bajo instrucciones de las mismas, lo cual zanja en parte la discusión relativa al sujeto activo en el sistema de responsabilidad empresarial, ya que es evidente la necesidad que exista una persona física que actúe en nombre o representación de la empresa, que a fin de cuentas terminan siendo los verdaderos sujetos activos, a pesar que actúen en representación de una persona jurídica ${ }^{43}$.

Por otra parte, al tratarse de una modalidad de responsabilidad particular, se pueden presentar problemas de autoría en relación a la actuación de personas en nombre de la persona jurídica que no reúnan las condiciones exigidas como sujetos cualificados, exigencia necesaria del tipo penal especial, lo que la doctrina denomina "actuación en nombre de otro".

La actuación en nombre de otro está regulada en el derecho español, específicamente en el artículo 31, que hace referencia a los representantes de las personas jurídicas empero su actuación es de hecho, indicándose que responden individualmente, aunque no concurran las condiciones exigidas cualificantes, siempre que tales circunstancias se den en la entidad o persona en cuyo nombre o representación obra ${ }^{44}$.

\footnotetext{
${ }^{40}$ SERRANO-GONZÁLEZ (1977), p. 767.

${ }^{41}$ MIR (2006), p. 200. Aduce que el Código Penal únicamente se refiere a acciones humanas.

${ }^{42}$ La doctrina cuando habla de acción lo hace incluyendo la omisión.

${ }^{43}$ MUÑOZ (2010), p. 455.

${ }^{44}$ MUÑOZ (2010), p. 455.
} 
El Código Orgánico Integral Penal no consagra norma alguna similar a la supra indicada, no obstante, hace referencia a la concurrencia de responsabilidades en el artículo $50^{45}$, explanando que no se extingue ni modifica la Responsabilidad Penal de las Personas Jurídicas si hay concurrencia de responsabilidades con personas naturales en la realización de los hechos.

Asimismo, es importante destacar que el artículo 49 analizado, consagra un numerus clausus de personas que pueden fungir como sujetos activos actuando de cierta manera en representación o en nombre de la persona jurídica, limitado expresamente a: quienes ejercen propiedad o control, órganos de gobierno o administración (responsabilidad colectiva), apoderados o mandatarios, representantes legales o convencionales, agentes, operadores, factores, delegados, terceros que contractualmente o no, se inmiscuyen en una actividad de gestión, ejecutivos principales o quienes cumplan actividades de administración, dirección y supervisión, así como quienes actúen bajo órdenes o instrucciones de las personas naturales citadas.

Lo indicado anteriormente en relación al artículo in commento, es diáfano en el sentido que se estatuye expresamente el catálogo de personas naturales que pueden realizar la acción en nombre de la persona jurídica, sin que sea posible hablar de personas jurídicas que desempeñen cargos similares, debe tratarse expresamente de personas que se puedan subsumir en las conductas antes descritas, es decir, que actúen expresamente bajo las figuras establecidas en el tipo $^{46}$.

Asimismo, vale destacar que, de la interpretación efectuada al artículo analizado, se puede deducir que el sistema ecuatoriano se maneja con el denominado sistema vicarial o de responsabilidad indirecta de la persona jurídica, en virtud de la cual las personas jurídicas serán responsables porque lo son las personas físicas que actúan en su nombre o representación y estas a su vez, transfieren a la persona jurídica su responsabilidad penal. Esto forma parte del denominado sistema de responsabilidad indirecta, que también se le denomina responsabilidad por representación, siendo el modelo de responsabilidad por atribución a la persona jurídica aquel que presupone la comisión de un hecho delictivo completo por una de las personas físicas integradas en su seno, normalmente por alguna de las que integran sus órganos o la representan ${ }^{47}$.

\subsection{La Persona Jurídica en el Derecho ecuatoriano: análisis del elemento normativo Persona Jurídica}

Los tipos penales se conforman por elementos descriptivos y elementos normativos, en el presente caso se presenta un elemento normativo medular para interpretar el aludido tipo, relativo al término "persona jurídica", el cual requiere una interpretación jurídica. Para ello, partimos de algunas generalidades que escinden en tres grandes tipos de personas jurídicas ${ }^{48}, 1$ ) personas jurídicas de derecho civil, 2) personas jurídicas de derecho mercantil ${ }^{49} y, 3$ ) personas jurídicas de derecho público.

\footnotetext{
${ }^{45}$ Artículo 50.- Concurrencia de la responsabilidad penal. - La Responsabilidad Penal de las Personas Jurídicas no se extingue ni modifica si hay concurrencia de responsabilidades con personas naturales en la realización de los hechos, así como de circunstancias que afecten o agraven la responsabilidad o porque dichas personas han fallecido o eludido la acción de la justicia; porque se extinga la responsabilidad penal de las personas naturales, o se dicte sobreseimiento. Tampoco se extingue la responsabilidad de las personas jurídicas cuando estas se han fusionado, transformado, escindido, disuelto, liquidado o aplicado cualquier otra modalidad de modificación prevista en la Ley.

${ }^{46}$ Esto guarda relación con la interpretación restrictiva de los tipos penales, derivada del principio de legalidad.

${ }^{47}$ SILVA (2003), p. 70.

48 Planteamiento realizado por BACIGALUPO (1997), p. 412.

${ }^{49}$ Igualmente existe un Reglamento para el Otorgamiento de Personalidad Jurídicas a las Organizaciones Sociales.
} 
En tal sentido, las primeras encuentran regulación en el Código Civil ecuatoriano, el cual realiza una definición genérica de persona jurídica a la persona ficticia, capaz de ejercer derechos y contraer obligaciones, y de ser representada judicial y extrajudicialmente ${ }^{50}$. En tal sentido, se denota que las personas jurídicas en general son aquellas susceptibles de tener derechos y obligaciones, actuando bajo representación legal. Las personas jurídicas en esta materia básicamente son las asociaciones (corporaciones en la legislación ecuatoriana) ${ }^{51}$ y las fundaciones.

Ahora bien, es importante destacar que para que se materialice o se constituya legalmente una persona jurídica, sea en cualquiera de las modalidades supra indicadas, es menester que se cumplan ciertos requisitos legales ${ }^{52}$, así, para el nacimiento de la persona jurídica, hay de por medio un convenio, un contrato o un ley, pero en cualquier caso el origen de estas personas morales se sustenta en un acto del poder político que da lugar al nacimiento de esta figura jurídica ${ }^{53}$.

Por otra parte, en relación a las personas jurídicas de derecho mercantil estas básicamente son constituidas por las sociedades de comercio que persiguen un fin de lucro e igualmente, tienen un régimen especial para su constitución, básicamente reguladas en la legislación mercantil ${ }^{54}$, siendo principalmente denominadas sociedades.

Por último, ubicamos a las personas jurídicas públicas, que se manifiestan mediante una mayor variedad de instituciones, que se definen desde una óptica diferenciadora de estas en relación a las personas privadas, distanciándose en dos aspectos básicos: 1.- Son entes públicos los que se encuentran con el Estado en una relación de derecho público de manera que se integran en su organización general; 2. Además adoptan una forma de Corporación o Fundación, pero no de Sociedad. Por ello las Sociedades mercantiles, ya sean de economía mixta, ya de único socio por parte de los entes públicos, no constituyen personas jurídicas de derecho público, sino que la estructura encuadra en el derecho privado ${ }^{55}$. Más allá de las definiciones o especificaciones que se puedan realizar es importante destacar que estas personas quedan fuera del ámbito de aplicación del régimen de Responsabilidad Penal de las Personas Jurídicas, por indicación expresa del artículo 49 del Código Orgánico Integral Penal ${ }^{56}$.

Ahora bien, explanadas algunas disposiciones generales relativas al alcance del elemento normativo "persona jurídica" queda claro que existen dos grandes bloques de personas pertenecientes al derecho privado (personas jurídicas civiles y personas jurídicas mercantiles), las cuales están expresamente determinadas en la legislación, por ello surge una problemática común en la temática, relativa a que algunos autores hacen referencia al término empresa, sin embargo, tal termino es factible siempre que la legislación así lo utilice, por contrario, no podemos equiparar a ambos conceptos, a pesar que pudieran considerarse sinónimos, ya que ello vulneraría el principio de legalidad penal ${ }^{57}$, la interpretación de los tipos penales debe ser literal ${ }^{58}$, prohibiéndose la

\footnotetext{
${ }^{50}$ Artículo 564. Se llama persona jurídica a una persona ficticia, capaz de ejercer derechos y contraer obligaciones civiles, y de ser representada judicial y extrajudicialmente. Las personas jurídicas son de dos especies: corporaciones y fundaciones de beneficencia pública.

${ }^{51}$ Artículo anterior.

${ }^{52}$ Art. 565.- No son personas jurídicas las fundaciones o corporaciones que no se hayan establecido en virtud de una ley, o que no hayan sido aprobadas por el presidente de la República.

${ }^{53}$ CEVALLOS (2010), p. 29.

${ }^{54}$ Bien sea en forma de Código de Comercio o leyes especiales. En ecuador rige la denominada ley de sociedades.

${ }^{55}$ GARCÍA-TREVIJANO (1956), p. 84.

${ }^{56}$ Artículo 49.- Responsabilidad de las personas jurídicas. - En los supuestos previstos en este Código, las personas jurídicas nacionales o extranjeras de derecho privado son penalmente responsables (...).

${ }^{57}$ BACIGALUPO (1996), pp. 58, 59 y 60.

${ }^{58}$ Artículo 13.- Interpretación. - Las normas de este Código deberán interpretarse de conformidad con las siguientes reglas: 1. La interpretación en materia penal se realizará en el sentido que más se ajuste a la Constitución de la República de manera integral y a los instrumentos internacionales de derechos humanos. 2. Los tipos penales y las penas se interpretarán en forma estricta, esto es,
} 
interpretación extensiva o analógica para interpretar in malam parte, tal como lo dispone el Código Orgánico Integral Penal, con lo cual debe excluirse cualquier interpretación que abarque otros términos como empresas o incluso, sociedades, asociaciones, corporaciones, fundaciones, entre otras, que actúen de hecho, es decir, consideramos que debe tratarse de personas jurídicas legalmente constituidas, ya que de lo contrario no son propiamente una persona jurídica, sino que actuarían al margen de la ley.

Asimismo, se hace referencia expresamente a personas jurídicas de carácter privado, excluyendo cualquier figura de carácter público, lo que nos lleva incluso a excluir (por principio de legalidad) a las personas jurídicas mixtas que posee capital privado y público.

Por otra parte, se aduce que se trata de personas jurídicas nacionales o extranjeras, aspecto que se va a determinar, conforme al acta constitutiva o de registro, a pesar que pueden existir personas jurídicas registradas o inscritas en diversos países, en todo caso, la norma abarca a cualesquiera, tanto patrias como de otros Estados.

Por último, el artículo 49 estudiado, consagra el elemento normativo referido a personas jurídicas nacionales o extranjeras, lo cual implica realizar diversas precisiones. En primer término, se hace referencia a personas jurídicas extranjeras sin especificar si se trata de personas jurídicas extranjeras domiciliadas en el Ecuador o en el extranjero, al respecto, en lo relativo a las personas jurídicas domiciliadas en el Estado ecuatoriano no existe problema alguno con respecto al alcance de la norma analizada, sin embargo, en relación a personas jurídicas extranjeras no domiciliadas en el país que operen en el país, deben ajustarse a ciertas normativas, tales como la legislación tributaria, contractual, procesal, entre otras ${ }^{59}$, en todo caso, se entiende que están operando en el país, a pesar de estar domiciliada en el extranjero ${ }^{60}$.

Asimismo, el incumplimiento de la referida normativa pudiera generar problemas en atención al alcance del tipo penal, ya que se podría decir que estas personas jurídicas no están legalizadas, sin embargo, consideramos que el tipo penal no distingue entre personas jurídicas que cumplan o no con la normativa que le corresponde, sino que estas realmente sean personas jurídicas, por tanto, no se presentan mayores problemas. Caso contrario, es el de aquellas personas jurídicas no domiciliadas en el Ecuador y cometen un delito (en el entendido que es a través de sus representantes) que implique aspectos de extraterritorialidad en aplicación de la ley penal, debemos aplicar las normas estatuidas en el numeral primero del artículo 14 del Código Orgánico Integral Penal, que en principio ordena que se aplique el principio de territorialidad (locus regit actum), o en su defecto, aplicar la ley penal ecuatoriana, en casos específicos, cuando la infracción (delito) implique otros problemas relacionados con el lugar de comisión del delito ${ }^{61}$, se debe acudir al numeral segundo y siguientes, del artículo in commento, que regulan los casos de extraterritorialidad de la aplicación espacial de la ley penal.

Ahora bien, en relación a la exclusión de la aplicación del régimen relativo a la Responsabilidad Penal de las Personas Jurídicas, por parte de personas jurídicas del Estado, en virtud que el artículo 49 analizado expresamente limita la responsabilidad al ámbito de las personas de

respetando el sentido literal de la norma. 3. Queda prohibida la utilización de la analogía para crear infracciones penales, ampliar los límites de los presupuestos legales que permiten la aplicación de una sanción o medida cautelar o para establecer excepciones o restricciones de derechos.

${ }^{59}$ Incluso el artículo 6 de la Ley de Compañías establece en el artículo 6.- Toda compañía nacional o extranjera que negociare o contrajere obligaciones en el Ecuador deberá tener en la República un apoderado o representante que pueda contestar las demandas y cumplir las obligaciones respectivas.

${ }^{60}$ En el caso de que una persona jurídica española cometa un delito en el extranjero, debe tenerse en cuenta lo dispuesto en el artículo 23.2 de la Ley Orgánica del Poder Judicial.

${ }^{61}$ El Artículo 14 regula lo relativo al ámbito espacial de aplicación de la ley penal. 
derecho privado, con lo cual las personas jurídicas de Derecho público quedan excluidas, esto se debe a que entre otras razones, en lo anómalo de que el Estado ejerza la potestad punitiva sobre sí mismo o sobre los organismos mediante los cuales ejerce otras potestades ${ }^{62}$.

\subsection{Elemento subjetivo (persecución de un beneficio para la persona jurídica)}

Asimismo, se establece un elemento subjetivo que debe estar presente para que se aplique el régimen de personas jurídicas y es el relativo al consagrado en el aludido artículo 49, que expresamente refiere que no hay lugar a la determinación de la responsabilidad penal de la persona jurídica, cuando el delito se comete por cualquiera de las personas naturales indicadas en el inciso primero, en beneficio de un tercero ajeno a la persona jurídica.

Visto lo indicado, es importante indicar que se trata de un elemento subjetivo, a pesar que su redacción no es la más idónea, sin embargo, se desprende que en la comisión del delito las personas naturales deben perseguir un beneficio para la persona jurídica, es decir, una finalidad extra del dolo de cometer el delito, en este caso, el beneficio debe ser perseguido para la persona jurídica y no para un tercer ajeno a la persona jurídica. Esto implica que no se permite utilizar a la persona jurídica como instrumento para beneficiar a un tercero, sin embargo, consideramos que pueden darse casos en los cuales un tercero se puede beneficiar conjuntamente con el representante de la empresa que se trate, así como coadyuvar como partícipe (extraneus) en la comisión del delito, por ello, excluirlo del todo puede generar problemas dogmáticos.

\subsection{Independencia de responsabilidad}

El artículo 49 del Código Orgánico Integral Penal establece que la responsabilidad penal de la persona jurídica es independiente de la responsabilidad penal de las personas naturales que intervengan con sus acciones u omisiones en la comisión del delito. Tal situación se presenta en la legislación española, por eso se aduce que la responsabilidad penal de la persona jurídica y de la persona física no se excluyen entre sí, por tanto, cabe que ambas sean responsables ${ }^{63}$.

\subsection{Supuestos previstos en el código (Numerus clausus de tipos)}

Al revisar el régimen de responsabilidad penal de las personas jurídicas, se desprende del artículo 49 analizado, ab initio que la persona jurídica será responsable "en los supuestos previstos en este código", aspecto que lleva a cuestionar si se trata de un númerus clausus, aspectos que podemos inferir del tratamiento que ha dado la doctrina comparada ${ }^{64}$, ya que al revisar el cuerpo del Código Orgánico Integral Penal, vamos a ubicar diversos tipos que expresamente invocan sanciones para personas jurídicas ${ }^{65}$, tal como se evidencia en las siguientes disposiciones del aludido Código:

En primer término, se consagra que las Graves violaciones a los derechos humanos y delitos contra el Derecho Internacional Humanitario, consagrados en la Sección Primera, son susceptibles

\footnotetext{
62 MUÑOZ (2010), p. 629.

${ }^{63}$ MUÑOZ (2010), p. 631.

${ }^{64}$ Especialmente la española.

${ }^{65}$ A pesar que existe una norma que establece un catálogo genérico de sanciones para las personas jurídicas, estatuido en el artículo 71 del Código Orgánico Integral Penal.
} 
de ser cometidos por personas jurídicas y además la pena a imponer a esta, es la consagrada en el artículo 90 del COIP, referida a una sanción de extinción.

Al respecto, vale destacar que esta pena no figura en las consagradas en el artículo 71 del Código Penal, que expresamente consagra un catálogo de penas, sin que se refleje la existencia de la extinción de la persona jurídica, aspecto que representa una afrenta al principio de legalidad penal que ordena el establecimiento de una pena previa que debe ser clara y diáfana. Asimismo, esto se traduce en una falta de coherencia y sistematización del sistema de Responsabilidad Penal de las Personas Jurídicas, ya que deben estar en sintonía las normas generales con las especiales sin que existan desfases entre unas y otras, ni tratamientos distintos.

Por otra parte, se plasman los siguientes tipos que abarcan Responsabilidad Penal de las Personas Jurídicas, Trata de personas, establece el artículo 94 que una persona jurídica puede ser responsable de este delito y la sanción será una multa; Diversas formas de explotación, Sección Tercera, consagrada en el artículo 109, que establece una sanción de multa a las personas jurídicas; Ocupación, uso ilegal de suelo o tráfico de tierras, plasmado en el artículo 201, se consagra una sanción de extinción conjuntamente con multa; Insolvencia fraudulenta, explanada en el artículo 205, abarcando pena de clausura definitiva de locales o establecimientos, conjuntamente con multa. Tráfico ilícito de migrantes, establecido en el artículo 213, que acarrea una pena de extinción. Producción, fabricación, comercialización y distribución de medicamentos e insumos caducados, plasmado en el artículo 217, que implica una pena de extinción y multa; Desatención del servicio de salud, tipificado en el artículo 218 que plasma una multa y clausura temporal; Delitos contra los derechos de los consumidores, usuarios y otros agentes del mercado, plasmado en el artículo 235 que implica una pena de multa; Delitos contra el derecho a la cultura, tipificado en el artículo 237, cuya pena para las personas jurídicas es la disolución; Retención ilegal de aportación a la seguridad social, consagrado en el artículo 242, cuya pena es la clausura hasta que se cancelen los valores adeudados; Falta de afiliación al Instituto Ecuatoriano de Seguridad Social, según el artículo 243 que acarrea pena de multa.

Igualmente, se estipula la Responsabilidad Penal de las Personas Jurídicas en los casos de Delitos contra el ambiente y la naturaleza (Pacha Mama), consagrados en el capítulo cuarto, según lo dispone el artículo 258, basadas en multas, clausuras temporales y definitivas, comisos y remediación de los daños ambientales (incluyendo los Delitos contra los recursos naturales no renovables estipulados en el artículo 267 que implica multa).

En el caso de la Defraudación tributaria, consagrado en el artículo 298, consagra un supuesto especial de Responsabilidad Penal de las Personas Jurídicas, específicamente en su primer aparte, en el cual se indica que cualquier persona jurídica, sociedad o entidad, que, aunque carente de personalidad jurídica ${ }^{66}$, que constituya una unidad económica o un patrimonio independiente de la de sus miembros, será sancionada con pena de extinción de la persona jurídica y multa.

Operaciones indebidas de seguros, según el artículo 316 del Código, serán responsables por las personas jurídicas, las personas que administren o autoricen las operaciones indebidas, la única pena que consagra es la relativa a privativa de libertad que recae exclusivamente sobre los sujetos indicados, excluyéndose de esa manera sin especificar la pena para los casos en los cuales se trate de personas jurídicas.

Por último, se estatuye la sección octava que consagra los Delitos Económicos (incluyendo blanqueo de capitales), consagra el artículo 325 que los aludidos delitos serán sancionados con

\footnotetext{
66 Observamos una excepción a lo señalado en relación a la exigencia de personalidad jurídica, es decir, que la persona jurídica efectivamente debe estar constituida legalmente.
} 
multa, clausura definitiva y extinción, conforme a grados, atendiendo a la pena privativa que acarree cada tipo.

\subsection{Penas para las Personas Jurídicas}

El estudio de las penas se corresponde con la función del Derecho penal y a pesar que la respuesta a la finalidad del derecho penal ha sido estudiada durante siglos y aún en nuestros días se sigue presentando la discusión. Lo cierto es que las corrientes que se imponen en la actualidad se perfilan hacia teorías mixtas que unifican aspectos relativos y absolutos en la imposición de penas, predominando siempre el carácter preventivo, político-criminal ${ }^{67}$.

En tal sentido, la pena fue concebida desde su teoría primigenia para ser impuesta a una persona natural, no obstante, observando la realidad legislativa de diversos países, así como la tendencia cada vez más aceptada de admitir la Responsabilidad Penal de las Personas Jurídicas, conlleva a precisar dos aspectos, en primer término, es claro que la persona jurídica siempre será una ficción manejada por un colectivo o grupo de personas que permiten erigir una persona jurídica, en tal sentido, en lo que atañe a la responsabilidad de directores y responsables de estas personas, son perfectamente responsables desde un punto de vista penal y los fines de la pena perfectamente los abarcan, en segundo término, en lo que respecta a la persona jurídica, las sanciones penales van en otro norte, ya que la pena no cumplirá los fines clásicos (tales como el de motivación o de política criminal, entre otros) que usualmente se les endilga a la pena, sino que responden a otros motivos.

Incluso, otras concepciones normativas facilitan la afirmación relativa a la capacidad de pena de las personas jurídicas, por ello los seguidores de esta corriente afirman que la pena no repara bienes, sino confirma la identidad normativa de la sociedad. Por ello, el Derecho penal no puede reaccionar frente a un hecho en cuanto lesión de un bien jurídico, sino solo frente a un hecho en cuanto quebrantamiento de la norma ${ }^{68}$.

Por otra parte, de igual manera vale destacar que existen objeciones relacionadas con aquellas conforme a la cual se dificulta asignarle carácter de pena a sanciones distintas de la privación o restricción de la libertad ambulatoria, como son necesariamente las que se pueden imponer a una persona jurídica, lo cual impediría distinguir entre sanciones penales y administrativas ${ }^{69}$.

Ahora bien, en relación a los motivos para la imposición de sanciones penales, y no simplemente de carácter administrativo, contra las personas jurídicas, debemos tener en cuenta en primer lugar una serie de aspectos tales como la idoneidad de la sanción para la eliminación de las ventajas obtenidas, la adecuación de la sanción a la capacidad de producción de la persona jurídica y la proporcionalidad de la sanción a la trascendencia del hecho ${ }^{70}$.

No cabe duda, que partiendo de la función de control que desempeñan las consecuencias jurídicas en el moderno Derecho penal, no caben dudas sobre la capacidad de aplicación de los fines de la pena a personas jurídicas, pues las personas jurídicas son sistemas dotados de sentido. La capacidad de aplicación de la pena atiende a la prevención general (efectos se deducen para otras personas jurídicas) y preventivo-especial (una persona jurídica se abstendrá antes que una persona física sancionada de volver a infringir la ley $)^{71}$.

\footnotetext{
${ }^{67}$ MIR (2006), p. 776. Este autor es partidario de aducir que se trata de medidas y no de verdaderas penas.

${ }^{68}$ JAKOBS (1996), p. 11.

${ }^{69}$ HERNÁNDEZ, (2010). p. 212.

70 DANNECKER (2001), p. 42

${ }^{71}$ DANNECKER (2001), p. 49.
} 
En el mismo sentido, al hablar de prevención general, en lo que a la prestación concierne, lo que más interesa aquí es cómo se muestra el reforzamiento de la fidelidad al Derecho en el ámbito empresarial, y en el ámbito preventivo-espacial, existen partidarios de este modelo que no confían en que la empresa con solo el estímulo de una multa sea capaz de autoorganizarse eficazmente y por ello proponen sanciones mucho más intervencionistas como la suspensión de la actividad económica, la intervención o hasta la disolución ${ }^{72}$.

Ahora bien, en relación a las penas aplicables a las personas jurídicas en el derecho ecuatoriano, el artículo 71 del Código Integral Penal establece, las siguientes:

Artículo 71.- Penas para las personas jurídicas. Las penas específicas aplicables a las personas jurídicas, son las siguientes:

1. Multa.

2. Comiso penal. Los actos y contratos existentes, relativos a los bienes objeto de comiso penal cesan de pleno derecho, sin perjuicio de los derechos de terceros de buena fe, que se reconocen, liquidan y pagan a la brevedad posible, quienes deberán hacer valer sus derechos ante la o el mismo juzgador de la causa penal. Los bienes declarados de origen ilícito no son susceptibles de protección de ningún régimen patrimonial.

3. Clausura temporal o definitiva de sus locales o establecimientos, en el lugar en el que se ha cometido la infracción penal, según la gravedad de la infracción o del daño ocasionado.

4. Realizar actividades en beneficio de la comunidad sujetas a seguimiento y evaluación judicial.

5. Remediación integral de los daños ambientales causados.

6. Disolución de la persona jurídica, ordenado por la o el juzgador, Código Orgánico Integral Penal en el país en el caso de personas jurídicas extranjeras y liquidación de su patrimonio mediante el procedimiento legalmente previsto, a cargo del respectivo ente público de control. En este caso, no habrá lugar a ninguna modalidad de recontratación o de reactivación de la persona jurídica.

7. Prohibición de contratar con el Estado temporal o definitivamente, según la gravedad de la infracción.

El anterior catálogo de penas merece expresar que se trata de un listado taxativo que presenta incongruencias, tal como se apuntó ut supra, ubicamos algunas disposiciones del sistema númerus clausus, que expresamente define las penas aplicables a estos entes, sin embargo, existen diversos tipos que hacen referencia a una pena de extinción, la cual no se encuentra estatuida en el artículo anterior. Así se sostenga que la clausura definitiva equivale a una extinción, en un estricto sentido técnico, son conceptos distintos, ya que son términos que aun cuando pudieran emplearse como sinónimos, en materia penal pueden afectar el principio de legalidad en lo atinente a la taxatividad y prohibición de interpretación analógica de la ley penal, por tal razón, se trata de una falla en el sistema de responsabilidad penal que debe ser corregida por el legislador en una próxima reforma, ya que se deben unificar los términos.

Por otra parte, se plasma la multa, clásica sanción en materia de responsabilidad penal de personas jurídicas, siendo en grandes rasgos, la alternativa más importante a la pena privativa de libertad es la pena de multa ${ }^{73}$, siendo esta empleada en otros ámbitos o áreas del derecho, tales como en el derecho administrativo. Igualmente, con respecto a esta pena usualmente se realizan ciertas críticas, que radican básicamente en la desigualdad que puede comportar entre personas con poder adquisitivo para responder y aquellas que no ${ }^{74}$, así como se enaltecen sus ventajas que

\footnotetext{
72 BAUCELLS (2013), pp. 177-178.

${ }^{73}$ JESCHECK (1980), p. 17 y el mismo autor, en referencia a Alternativas, p. 28.

${ }^{74}$ MIR (2006), p. 712.
} 
radican básicamente en que afectan bienes menos sensibles que la libertad, como lo es el patrimonio, sin privar al ciudadano de su entorno, trabajo y aspectos sociales ${ }^{75}$, es decir una pena más humana y menos invasiva. Debe entenderse que esta pena actúa en situaciones de delitos que no son considerados en términos generales, graves.

Ahora bien, la segunda pena, es el comiso penal, que radica en el cese de actos y contratos relativos a bienes objetos de comiso penal (con la salvedad que se protegen los derechos de terceros de buena $\mathrm{fe}^{76}$ ), sin embargo, al revisar la pena de comiso penal para personas naturales estatuido en el artículo 69 del COIP, relativo a penas restrictivas de los derechos de propiedad, indicándose que se procederá al comiso penal en casos de delitos dolosos y recae sobre bienes cuando son instrumentos, productos o réditos en la comisión del delito. Visto lo anterior, se trata de comisos de distintas naturalezas, ya que el primero (aplicado a personas jurídicas) va destinado al cese de actos y contratos relativos a bienes, en cambio, el segundo (dirigido a personas naturales), estriba en bienes cuando son instrumentos, productos o réditos en la comisión del delito.

Por otra parte, la tercera pena se refiere a la clausura temporal o definitiva, según la gravedad de la infracción (delito) o del daño causado, siendo dejada esta medición al libre arbitrio del juez, en virtud el Código Orgánico Integral Penal no establece un baremo para cuantificar o determinar la gravedad del delito o del daño. Adicionalmente, en lo que atañe a la clausura definitiva, que, en países como España y Francia, no se ha aplicado regularmente, en virtud que esta pena conlleva a una muerte de la persona jurídica, el cese de toda su actividad, prevaleciendo el impacto que puede generar a nivel laboral, así como el impacto a otras empresas que pueden llegar a depender de esta, otras palabras, son intereses económicos los que han prevalido a los argumentos político-criminales ${ }^{77}$.

Asimismo, fácilmente surge el cuestionamiento desde un punto de vista constitucional principista, al enarbolar la prohibición de penas de muerte o perpetuas, que conlleva a equiparar la clausura definitiva a una de estas penas. Sin embargo, la solución que se ha dado a tal problema es invocar el carácter ilícito de la sociedad, es decir, que la disolución o la clausura definitiva solo deban acordarse cuando se trate de asociaciones ilícitas, esto es, de la comisión estructural de delitos, y no si se trata de uno o varios delitos cometidos incidentalmente en el marco de una empresa lícita ${ }^{78}$. Esta interpretación la encontramos más acertada, a pesar que la legislación ecuatoriana no hace mención de lo indicado, empero, pudiera desprenderse de la interpretación de lo que debe como entenderse como un delito grave o que ocasione daños sustanciales.

Por otra parte, la cuarta pena estriba en realizar actividades en beneficio de la comunidad. Vale destacar que la norma no especifica quién desplegará estas actividades, es decir, si debe ser satisfecha por parte de la persona natural que actúa en representación de la persona jurídica, o en su defecto, por la jurídica, sin distingo de quién lo realice tratándose de cualquier empleado.

Igualmente, esta usualmente es empleada en diversos ordenamientos jurídicos ${ }^{79}$, siendo obligatoria en algunos casos y otros se requiere el consentimiento del penado ${ }^{80}$, en tal sentido, la necesidad de presentación del consentimiento para la imposición del trabajo comunitario ha sido explicada por un sector mayoritario de la doctrina por el debido respeto a la contravención

\footnotetext{
75 MIR (2006), p. 712.

${ }^{76}$ Indica la disposición analizada que "Los bienes declarados de origen ilícito no son susceptibles de protección de ningún régimen patrimonial".

${ }_{77}$ BAUCELLS (2013), p. 212.

${ }^{78}$ SILVA (2001), p. 354.

${ }^{79}$ En el Código Orgánico Procesal Penal (2012). Se emplea en la suspensión condicional del proceso, así como en la imposición de la multa.

${ }^{80}$ Tal como ocurre en el ordenamiento jurídico español. Artículo 49 del Código Penal establece el consentimiento obligatorio. Asimismo, el 53 ejusdem, en la misma línea reitera esa necesidad, reflejada de igual manera en el artículo 2.
} 
constitucional al de los trabajos forzados ${ }^{81}$. Asimismo, no se determina el alcance de las aludidas actividades, que pueden ser variadas y en ocasiones incluso pueden tornarse en excesivas, por ello se sugiere contar con una determinación de su alcance, plazo máximo de cumplimiento, determinación de duración de la jornada, y respetarse el cumplimiento del principio de flexibilidad que debe regir en la ejecución de esta pena que permita la compatibilidad con el normal desarrollo de las actividades cotidianas de la persona ${ }^{82}$.

Ahora bien, la quinta pena consiste en la remediación integral de los daños ambientales causados, los cuales pueden presentar confusión con respecto a la denominada responsabilidad civil derivada del delito, que implica que el hecho que la ley describe como delictivo, además de producir un daño social, por lo que se hace acreedor de una pena, puede ocasionar un daño privado o la lesión de intereses individuales que son susceptibles de ser reparados o indemnizados, lo que hace surgir la responsabilidad civil o la obligación de reparar el daño causado ${ }^{83}$, por tanto, esta responsabilidad abarca la restitución, la reparación del daño causado y la indemnización de perjuicios, así que la denominada remediación integral de los daños ambientales va implícita en el concepto de responsabilidad civil derivada del delito. Sin embargo, hay que tomar en consideración que los daños ambientales son de difícil reparación, y en algunas ocasiones, por ejemplo, si se trata de la pérdida de especies, son irreparables. Sin embargo, cuando nos encontramos con que el daño ambiental ya se ha producido, el principio de la reparación del daño ambiental, conocido también como reparación in natura, exige que no quede a elección del ofendido la forma de reparación, sino que se prefiera esta opción en lugar de la tradicional indemnización ${ }^{84}$.

En relación a la sexta pena, esta radica en la disolución de la persona jurídica, sin embargo, según la redacción del numeral, se presentan problemas de interpretación ya que se hace referencia a la disolución de la persona jurídica, ordenada por el juzgador, en el país en el caso de personas jurídicas extranjeras, lo cual se traduce en que esta disolución va referida a las personas jurídicas extranjeras. Aquí operan las mismas consideraciones efectuadas con relación a la clausura definitiva y se reafirma lo sostenido en esta investigación en relación a la "extinción" (plasmada en diversos artículos como pena para las personas jurídicas) que no figura expresamente en el catálogo de penas a aplicarse a las personas jurídicas. Igualmente, en esta pena se estatuye que se liquidará el patrimonio a cargo del respectivo órgano y no habrá lugar a ninguna modalidad de reactivación o contratación, lo cual se traduce en su fenecimiento.

Por último, se consagra la prohibición de contratar con el Estado, bien sea de manera temporal o definitiva, sanción que se asemeja a algunas de carácter definitivo (como la clausura definitiva y la disolución), esta prohibición aun cuando permite que la persona jurídica siga operando, se ve afectada en la posibilidad de contratar con el Estado, tal situación es incongruente desde un punto de vista objetivo en el sentido que si la persona jurídica fue sancionada penalmente y se le prohibirá contratar con el Estado en virtud de su conducta en aras que no afecte el patrimonio público, ya que de igual manera puede afectar el patrimonio privado, al permitirse contratar con otros organismos privados, es decir, la afectación no puede ser únicamente vista desde un plano estatal, sino global.

\footnotetext{
${ }^{81}$ BLAY (2006), p. 170.

82 BLAY (2006), p. 235

${ }^{83}$ ARTEAGA (2006), p. 438.

${ }^{84}$ GARCÍA (2007), pp. 1-2.
} 
Lo anterior, se colige con la tendencia, en parte de la unión europea ${ }^{85}$, así como de algunos legisladores ${ }^{86}$ específicos, que han mostrado iniciativas o tipificación de la denominada corrupción privada, lo cual implica aceptar que en la actualidad, es imprescindible tipificar el delito de corrupción, para atender las implicaciones entre corrupción pública y privada, la corrupción ha dejado de ser un negocio privado y aislado entre funcionario y particular, para convertirse en un modo más de articulación de articulación de relaciones económicas entre agentes públicos y privados ${ }^{87}$, por tal razón, se apoya tal iniciativa, en virtud que la corrupción en el mundo global actual dejó de pertenecer exclusivamente al ámbito privado.

Asimismo, se establece una valoración por parte del juez de la gravedad del delito para que se imponga la prohibición de manera temporal o definitiva.

El catálogo difiere de los numerus clausus de otros ordenamientos jurídicos que incluyen otras penas o medidas que recaen sobre las personas jurídicas que incurren en responsabilidad penal, entre las que destacan: la intervención de la persona jurídica "en aras de salvaguardar derechos", la prohibición de realizar en el futuro operaciones relacionadas con aquellas en las que incurrió en delito, establecimiento de límites temporales para la clausura o la suspensión.

\subsection{Extinción de la Responsabilidad Penal de las Personas Jurídicas, excepciones al régimen penal ordinario. (Concurrencia de la responsabilidad penal)}

En relación a la extinción de la Responsabilidad Penal de las Personas Jurídicas, establece el artículo $50^{88}$ del Código Orgánico Integral Penal, que esta no se extingue ni se modifica, si hay concurrencia de responsabilidades (personas naturales y personas jurídicas), es decir, porque se extinga la responsabilidad penal de las personas naturales ${ }^{89}$ e incluso, se dicte sobreseimiento.

Tal señalamiento conlleva a afirmar que la responsabilidad penal de las personas naturales es independiente la Responsabilidad Penal de las Personas Jurídicas. De igual manera apunta el referido artículo que no se extingue la Responsabilidad Penal de las Personas Jurídicas, cuando se fusionan, transforman, escinden, disuelven, liquidan o modificado, por tanto, la responsabilidad subsiste a pesar que se presente alguno de los mencionados fenómenos.

\subsection{Responsabilidad Penal de las Personas Jurídicas y aspectos Procesales}

Uno de los aspectos que usualmente es relegado al estudiarse la Responsabilidad Penal de las Personas Jurídicas es el relacionado a la persona jurídica y el régimen procesal, en virtud que el proceso penal, aun cuando forma parte de la teoría general del proceso, este presenta particularidades propias por tratarse de un mecanismo instrumental para imponer un delito, el cual va dirigido en principio a una persona natural, es decir, su concepción obedece al procesamiento de personas físicas.

En tal sentido, existen ciertos actos procesales que por su naturaleza están dirigidos a personas físicas ${ }^{90}$ y que, en caso de tratarse de personas jurídicas, merecen una especial regulación.

\footnotetext{
${ }^{85}$ Convenio del Consejo de Europa, 27-I de año 1999.

${ }^{86}$ Caso del artículo 286 bis del Código penal español o el artículo 47 de la Ley Contra la Corrupción venezolana, entre otras legislaciones.

${ }^{87}$ NIETO (2002) p. 61.

${ }^{88}$ Artículo 50.- Concurrencia de la responsabilidad penal. (...) Código Orgánico Integral Penal.

${ }^{89}$ El artículo separa la muerte como causa de extinción de la responsabilidad penal de las personas naturales, cuando est a es una de las causas que extingue dicha responsabilidad.

90 Por ejemplo, la imposición de una pena privativa de libertad, el acto de imputación formal, admisión de hechos, declaración del imputado, entre otros.
} 
Ahora bien, de la revisión al Código Orgánico Integral Penal, en su parte adjetiva, únicamente hace referencia a las personas jurídicas en dos supuestos, el primero, relacionado con las medidas cautelares para personas jurídicas, establecido en el artículo 550, en el cual se plasman tres medidas cautelares, 1.- Clausura provisional; 2.- Suspensión temporal de actividades y 3.- Intervención por parte del ente público competente.

En relación a las medidas indicadas, estas realmente se erigen como medidas preventivas, en virtud que las medidas cautelares propiamente dichas ${ }^{91}$, en virtud que estas últimas persiguen asegurar un eventual fallo ${ }^{92}$, a diferencia de las medidas de carácter preventivo ${ }^{93}$ que no tienen naturaleza cautelar, que persiguen garantizar derechos o proteger a las partes intervinientes en un proceso.

Por otra parte, el segundo supuesto relacionado con las personas jurídicas está estatuido en el artículo 622, que señala los requisitos de la sentencia, específicamente el numeral 7, que indica que cuando se determine la responsabilidad penal de la persona jurídica, el juzgador deberá verificar los daños a terceros para poder imponer la pena. Este aspecto guarda relación con la responsabilidad civil derivada del delito, la cual es aplicada en sede penal.

\section{Conclusiones}

Históricamente se ha manejado la discusión relativa a la Responsabilidad Penal de las Personas Jurídicas, predominando de manera primigenia la concepción de denominado societas delinquere non potest, que significa que las sociedades no pueden delinquir, en virtud de la incapacidad de acción, de culpabilidad y de pena.

Ahora bien, a pesar de lo anterior, se viene abriendo paso en la doctrina el nuevo paradigma del societas delinquere potest, esto generado en principio por la regulación por parte de diversos códigos penales y demás normas de derecho penal colateral, así como la construcción y reclamo por parte de la dogmática jurídico-penal de constructos que permitan este tipo de responsabilidad, para ello, se ha acudido a un sinfín de teorías que procuran sustentar este tipo de responsabilidad penal, sin que a la fecha exista consenso pleno para esta figura colectiva de responsabilidad.

Ante tal escenario, el Derecho penal ecuatoriano se abrió paso a esta nueva concepción de admitir la Responsabilidad Penal de las Personas Jurídicas con la entrada en vigencia del Código Integral Penal (COIP), instrumento que consagró expresamente la responsabilidad de estos entes, estableciendo un régimen para determinarla.

En tal sentido, se consagra la responsabilidad de las personas jurídicas nacionales o extranjeras, excluyendo a las personas de carácter púbico, estableciéndose un catálogo de sujetos naturales que actúan con determinado carácter (administradores, apoderados, representantes, ejecutivos, supervisores, entre otros sujetos) que necesariamente deben girar órdenes o instrucciones para que la persona jurídica sea responsable. Por otra parte, se exige un elemento

\footnotetext{
${ }^{91}$ BELLO (2004) pp. 110-111. Hace referencia a la confusión de conceptos jurídicos, indicando que: se mezclan funciones jurisdiccionales con administrativas, sin tomar en cuenta la naturaleza jurídica del instituto que se hace valer y las consecuencias jurídicas que tan indebida utilización conlleva a la Ciencia del Derecho.

${ }_{92}$ Tutela cautelar como especie de tutela preventiva, que se traduce en la posibilidad de adopción de medidas con la finalidad de asegurar el fallo. ORTíZ-ORTíz (2015), p. 54.

${ }^{93}$ 1.- Medidas preventivas sobre pruebas

2.- Medidas preventivas de protección a derechos o garantías constitucionales.

3.- Medidas de tutela anticipada por mandato de la propia constitución.

4.- Medidas preventivas de tutela de derechos.

5.- Medidas preventivas que procuran la efectividad y eficacia de un proceso judicial. (Medidas cautelares. ORTíz-ORTíz (2015), p. 87).
} 
subjetivo relativo a que los aludidos sujetos deben actuar en beneficio propio o de sus asociados, excluyéndose el beneficio perseguido para terceros.

Por otra parte, se consagra un númerus clausus de tipos que pueden ser abarcados por la Responsabilidad Penal de las Personas Jurídicas, tales como los delitos contra el Derecho Internacional Humanitario, trata de personas, ocupación ilegal de suelo o tráfico de tierras, insolvencia fraudulenta, tráfico de migrantes, producción, fabricación y distribución de medicamentos caducados, desatención del servicio de salud, delitos contra los derechos de los consumidores, retención ilegal de aportación a la seguridad social, falta de afiliación al Instituto ecuatoriano de Seguridad Social, delitos contra el ambiente, defraudación tributaria, operaciones indebidas de seguros y delitos económicos.

En relación a las penas, el Código Orgánico Integral Penal hace referencia a penas y no a medidas, como suele ocurrir en otras legislaciones. Adicionalmente, se establece un catálogo de penas que van desde una multa, hasta la clausura definitiva o disolución de la persona jurídica, sin embargo, más allá del catálogo de penas que pueden aplicarse a una persona jurídica, las mismas no se corresponden con algunas especificadas en diversos tipos penales, como ocurre en el caso de la extinción, la cual no figura expresamente en el aludido catálogo.

Por otra parte, se consagra en relación a la extinción de la responsabilidad penal que esta no se extingue ni modifica, si existe concurrencia de personas naturales y jurídicas, siendo independiente la Responsabilidad Penal de las Personas Jurídicas de las personas naturales.

Por último, en relación a las personas jurídicas y el ámbito procesal se evidencia que no existe un procedimiento específico en relación a la Responsabilidad Penal de las Personas Jurídicas, bien sea porque finalmente se trata de procesar a personas naturales que actúan en nombre o representación de las personas jurídicas, sin embargo, se consagra un régimen especial de medidas que el Código Orgánico Integral Penal denomina cautelares, no obstante se trata de medidas preventivas, que persiguen garantizar derechos o proteger a las partes intervinientes en un proceso. Asimismo, antes de imponerse una pena a una persona jurídica, debe especificarse o verificarse los daños ocasionados a terceros, lo cual está relacionado con la responsabilidad penal derivada del delito, aplicada en sede penal.

\section{BIBLIOGRAFÍA CITADA}

AGUDO, ENRIQUe Y JAÉN, MANUEL (2016): Derecho penal de las personas jurídicas (Madrid, Dykinson).

ARTEAGA, ALBERTO (2006): Derecho penal venezolano (Caracas, McGraw Hill Interamericana).

BACIGALUPO, ENRIQUE (1996): Manual de derecho penal parte general (Bogotá, Temis).

BACIgALUPO, SILVINA (1997): "La Responsabilidad Penal de las Personas Jurídicas. Un estudio sobre el sujeto del derecho penal". Disponible https://repositorio.uam.es/bitstream/handle/10486/4345/29501_bacigalupo_saggese_silvina.pdf ?sequence=1\&isAllowed=y [visitado el 12 de julio de 2019].

BAJO, MIGUEL Y BACIGALUPO, SILVINA (2010): Derecho penal económico, 2o edición (España, Editorial Universitaria Ramón Areces). 
BAJO, MIGUEL (2009): "La responsabilidad penal colectiva", en: Cuadernos de política criminal (№ 98) Madrid, Dykinson, pp. 31-70.

BASABE, SANTIAGO (2003): "Responsabilidad Penal de las Personas Jurídicas desde la teoría de los sistemas". Disponible en: http://repositorio.uasb.edu.ec/bitstream/10644/219/1/SM45-BasabeResponsabilidad\%20penal\%20de\%20las\%20personas\%20jur\%c3\%addicas\%20desde\%20la\%20teor \%c3\%ada\%20de\%20sistemas.pdf [visitado el 12 de julio de 2019].

BAUCELLS, JOAN (2013): "Las penas previstas para la persona jurídica en la reforma penal de 2010. Un análisis crítico", en: Estudios penales y criminológicos. Disponible en: https://www.researchgate.net/publication/322978152_Las_penas_previstas_para_la_persona_jur idica_en_la_reforma_penal_de_2010_un_analisis_critico_[visitado el 12 de julio de 2019].

BELLO, MARILÚ (2006): "Tutela preventiva, medidas cautelares y su vinculación con la tutela judicial efectiva". Disponible en: http://biblioteca2.ucab.edu.ve/anexos/biblioteca/marc/texto/AAQ3950.pdf [visitado el 12 de julio de 2019].

BLAY, ESTER (2006): "La pena de trabajo en beneficio de la comunidad". Disponible en: https://www.tdx.cat/bitstream/handle/10803/5084/ebg1de1.pdf?sequence=1\&isAllowed=y [visitado el 12 de julio de 2019].

BOLdova, MIGUel (2013): "La introducción de la Responsabilidad Penal de las Personas Jurídicas en la legislación española", en: Estudios penales y criminológicos. Disponible en: http://www.usc.es/revistas/index.php/epc/article/download/1395/1667 [visitado el 12 de julio de 2019].

CABEZA, DANIEL (2018): "La vigencia del Código de Comercio de 1890, Responsabilidad Penal de las Personas Jurídicas", en: Revista del Instituto de Investigaciones Jurídicas. México, Universidad Nacional Autónoma de México, pp. 129-144.

CEVALLO, VÍCTOR (2010): Nuevo compendio de derecho societario (Quito, Editorial Jurídica Ecuador).

DANNeCKer, Gerhard (2001): "Reflexiones sobre la Responsabilidad Penal de las Personas Jurídicas", en: Revista Penal (№ 7), pp. 40-54.

díAZ, CARMEN Y ChANJAN, RAFAel (2016): "La Responsabilidad Penal de las Personas Jurídicas: un estudio comparado entre España y el Perú", en: Revista de la Facultad de Derecho Pontificia del Perú (№ 77), pp. 349-379.

DAMASCHIN, MIRCEA Y GORUNESCU, MIRELA (2014): "La Responsabilidad Penal de las Personas Jurídicas. El caso rumano”, en: Eguzkilore (№ 28), pp. 145-165.

DE LA CUESTA, JOSÉ Y PÉREZ, ANA (2013): "La Responsabilidad Penal de las Personas Jurídicas en el marco europeo. Las directrices comunitarias y su implementación para los Estados”, en: Euskadi (№ 2), pp. 52-76. 
FEIJOO, BERNARDO (2002): Sanciones para Empresas por Delitos contra el Medio Ambiente, 1ra edición (Madrid, Civitas Ediciones S.L.).

GARCÍA, TANIA (2007): "El principio de la reparación del daño ambiental en el derecho internacional público, Una aproximación a su recepción por parte del derecho mexicano", en: Anuario Mexicano de Derecho Internacional. Ciudad de México, Universidad Nacional Autónoma de México. Disponible en: https://revistas.juridicas.unam.mx/index.php/derechointernacional/article/download/207/346 [visitado el 12 de julio de 2019].

GARCÍA-TREVIJANO, JOSÉ (1956): “Las personas jurídico-públicas en el Código civil y en la legislación de arrendamientos urbanos”, en: Revista de administración pública (№ 20), pp. 81-112.

GRANADOS, CARLOS (2007): "Análisis Jurisprudencial de la Responsabilidad de las Personas Jurídicas en el Ámbito Penal", en: Responsabilidad Penal de las Personas Jurídicas, Derecho Comparado y Comunitario (№ 115), pp. 125-156.

GONZÁLEZ, ELIENAI (2013): "Responsabilidad Penal de las Personas Jurídicas y sus implicaciones políticocriminales", en: Revista del Ministerio Público (№ 13), pp. 59-97.

GÓMEZ, CARLOS (2006): La Responsabilidad Penal de las Empresas en los EE. UU (Madrid, Editorial Universitaria Ramón Areces).

HERNÁNDEZ, HÉCTOR (2010): “La introducción de la Responsabilidad Penal de las Personas Jurídicas en Chile”, en: Revista de política criminal (Vol. 5, № 9), pp. 207-236.

JAKOBS, GÜNTHER (1996): Sociedad, Norma y persona en una teoría de un Derecho Penal funcional (Colombia, Universidad Externado de Colombia).

JESCHECK, HANS-HEINRICH (1980): Rasgos fundamentales del movimiento internacional de reforma del Derecho penal en La Reforma del Derecho penal (España, Editorial Bellatera).

MIR, SANTIAGO (2006): Derecho penal parte general, 8a edición (Barcelona, Reppertor). (1982): Introducción a las bases del derecho penal (Madrid, Editorial Bosch).

MUÑOZ, FRANCISCO Y GARCÍA, MERCEDES (2010): Derecho penal parte general, 8ae edición (Valencia, Tirant Lo Blanch).

NIETO, ADÁN (2008): "La Responsabilidad Penal de las Personas Jurídicas: Esquema de un Modelo de Responsabilidad Penal”, en: Nueva Doctrina Penal (№ 1), pp. 125-159.

(2002): "La corrupción en el sector privado (Reflexiones desde el ordenamiento español a la luz del Derecho comparado)", en: Revista Penal (№ 10), pp. 55-69.

ORTíz-ORTíZ, RAFAEL (2015): Tutela preventiva y cautelar (Valencia, Editorial Fronésis). 
PÉREZ, JACINTO (2014): Sistema de Atribución de la Responsabilidad Penal de las Personas Jurídicas (Madrid, Dykinson).

ROBLES, RICARDO (2006): “¿Delitos de Personas Jurídicas? A Propósito de la Ley Austriaca de Responsabilidad de las Agrupaciones por Hechos Delictivos", en: In Dret Revista para el Análisis del Derecho (№ 2), pp. 1-25.

ROXIN, CLAUS (1997): Derecho penal parte general. Fundamentos de la teoría del Delito (Traducc. Diego Manuel Luzón Peña, Madrid, Civitas), Tomo I.

SILVA, JESÚS (2001): "La Responsabilidad Penal de las Personas Jurídicas y las consecuencias accesorias del artículo 129 del Código penal”, en: Manuales de formación continuada (№ 14), pp. 308-364.

SILVA, JESÚS (2003): Normas y acciones en derecho penal (Buenos aires. Hammurabi).

ZAFFARONI, EUGENIO (2005): Reflexiones sobre el Derecho Penal Ambiental. Estudios sobre Justicia Penal. Homenaje al Profesor Julio B.J. Maier (Buenos Aires. Editores del Puerto).

\section{NORMAS JURÍDICAS CITADAS}

CÓDIGO CIVIL DE ECUADOR. Registro Oficial Suplemento № 46, 24 de junio de 2007.

CÓDIGO ORGÁNICO INTEGRAL PENAL DE ECUADOR. Registro Oficial № 180, 10 de febrero de 2014.

CONVENIO DEL CONSEJO DE EUROPA, 27-I. 7 de mayo de año 1999

DECRETO EJECUTIVO № 193, Reglamento para el Otorgamiento de Personalidad Jurídicas a las Organizaciones Sociales. Registro Oficial Suplemento № 109, 27 de octubre de 2017.

DECRETO № 9.042, Código Orgánico Procesal Penal de Venezuela. Gaceta Oficial № 6009, 17 de diciembre de 2012.

DECRETO № 1.402, Ley de Reforma a la Ley Contra la Corrupción. Venezuela, Gaceta Oficial № 6155, 19 de noviembre de 2014.

DECRETO LEY № 400/83, Vigésima Modificación del Código Penal Portugués. Diario da República № 170, 04 de septiembre de 2007.

LEY DE COMPAÑÍAS DEL ECUADOR. Registro Oficial № 312, 05 de noviembre de 1999.

LEY № 10/1995, Código Penal de España. Boletín Oficial № 281, 24 de noviembre de 1995.

LEY № 278/2006, Código Penal de Rumania. Monitorul Oficial, 12 de julio de 2006.

LEY № 20.393. Diario Oficial de Chile, 02 de diciembre de 2009. 
LEY № 30424, Ley que regula la responsabilidad administrativa de las personas jurídicas por el delito de cohecho activo transnacional. Diario Oficial del Bicentenario "El Peruano" № 583798, 21 de abril de 2016.

LEY ORGÁNICA DEL PODER JUDICIAL. España, Boletín Oficial № 157, 02 de julio de 1985.

LEY ORGÁNICA № 5/2010. España, Boletín Oficial del Estado № 152, 23 de junio de 2010.

PROYECTO DE LEY ORGÁNICA № 121/000065. España, Boletín Oficial de las Cortes Generales № 66-7, 01 de abril de 2015. 